\title{
EXPLORATION OF SELF-EXPRESSION TO IMPROVE L2 WRITING SKILLS
}

\author{
Verbra Pfeiffer ${ }^{1}$ and Sivakumar Sivasubramaniam ${ }^{2}$ \\ University of Stellenbosch ${ }^{1}$ \\ University of the Western Cape ${ }^{2}$
}

This article focuses on and explores the issue of teaching students to write with some level of fluency. In light of this, it investigates the use of expressive writing which can develop as the mainstay approach to help students improve their academic writing skills. Teaching students to write with confidence is always a daunting undertaking for any teacher, even more so when they are at a tertiary level. This study was conducted over a semester where a qualitative methodology was used to study autobiographical writing, journal entries and personal-response writing. Our results show that students' writing improved over a continuum of writing tasks of an evolutionary/daily living nature, through which we explored their self-expression. The study is predicated on the dynamics and fall-outs of L2 writing at a tertiary setting in Cape Town. The data provided by the fourteen participants featured in our study were meant to identify the kinds of strategies that could assist L2 students with English Language writing tasks. By the same token, the study was meant to offer useful insights into the educational practice and prevalence of writing for self-expression.

Keywords: expressive writing, self-expression, qualitative methods, journal entries, social aspects, cognitive aspects, noticeable students and distinguished students.

\section{POINT OF DEPARTURE}

Writing is often perceived as a difficult and complex activity by the current generation of students. Caught in a world of electronic gadgetry, visual culture and information overload, they neither appreciate the educational value of writing nor do they understand the sense of personal gratification it may instil in them.

We are aware that learning to write often begins with the mastery of producing legible letters and basic spelling (Abbott, Berninger \& Fayol, 2010) and that once these skills are attained, young writers attempt to master basic grammar and sentence structure. This is to suggest that writers begin to focus on text cohesion (McCutchen, 1986; Witte \& Faigley, 1981), syntactic structures (Hunt, 1965; McCutchen \& Perfetti, 1982), and cognitive strategies such as planning and revising (Abbott et al., 2010; Berninger et al., 1991). Based on these insights conventional wisdom dictates that teachers should follow a process approach to writing by following the stages of planning, drafting and revising: in that order. However, we were not convinced that the various stages mentioned above and their concomitant procedures and parameters (within which learning to write takes place) could serve as a motivation for students to express themselves in writing. To the contrary, these procedures and protocols (text cohesion, syntactic structures, cognitive strategies) appeared to overemphasize students' adherence to conventionality, grammaticality and linearity in their writing, thereby 
precluding them from using their writing as an instrument of free and fluent self-expression (Bilton \& Sivasubramaniam, 2009; Nunn and Sivasubramaniam, 2011; Sivasubramaniam, 2004). We were curious to find out if expressive writing can break down the barriers that L2 students face when they are asked to do academic writing.

As our research views writing as an expressive meaning structure, we encouraged the students to construct truly personal meanings. In this respect, the writing done by the students in our study is situated writing which was primarily intended to provoke self-expression (Kern, 2000; Kohonen et al., 2001). Furthermore, the students' writing by virtue of its rich subjectivity, challenges the acquisition metaphor, which is characteristic of a universalist epistemology (Pavlenko, 1998: 140). Our intention with these writing exercises was to allow our students the freedom to explore their thoughts on paper, by writing about daily events.

In this study, like many past studies, we focus on the linguistic factors that develop as writers mature (Berninger et al., 1994; Haswell, 2000; Hayes \& Flower, 1980; Perfetti \& McCutchen, 1987). In this study we focus specifically on writing development in young adults (Crossley et al., 2011). In order to promote learning through personal response and experience, we looked to literature of an evolutionary nature, which we define as literature that affects and exhibits emotions, motives, features of personality and forms of cognition. We believed that literature of this nature can facilitate the deployment of a writing pedagogy that can foster expressive writing. We therefore decided to lay the groundwork for using literature of daily living, which constitutes as well as underlies students' joys, fears, sorrows, abstractions, hopes and intuitions and help them become better writers with the help of the space and synergy that accrues via self-expression. This prompted us to pose the following research questions in this paper:

1. In which way can expressive writing help students?

2. How can literature of daily living improve students' writing?

3. Can personal-response techniques help improve fluency in writing?

\section{THEORETICAL FRAMEWORK}

Expressive writing has been identified as a manner of making connections between the known and the new on paper and it can also be defined as writing for the purpose of displaying knowledge or supporting self-expression (Graham \& Harris, 1989; Russell, Baker \& Edwards, 1999). Expressive writing can be likened to thinking on paper and this is something that one probably does every day in the course of one's research, composition, and planning processes (Foulk \& Hoover, 1996). We believed in encouraging our students to produce literature of daily living in which they would feel free to voice and address their fears, joy, hopes, doubts and initiatives which we thought would serve as the route of their expressive writing. We, therefore, argue that the stimulus for expressive writing lies in a sociocultural view of language, which puts writing at the heart of a literate society (Bilton \& Sivasubramaniam, 2009: 318).

In addition, to understand a question like "what is expressive writing?" one has to understand the purpose, which is to express thoughts, feelings and emotions rather than to simply convey information. We developed a growing belief in expressive, self-actualizing writing which turned attention away from the structuring of essays and correction of errors to creativity and self-discovery through journals in which students wrote without any fear of intimidation, 
grammar correction, teacher-dictated topics, critical comments or grades (Bilton \& Sivasubramaniam, 2009: 303). We argue that expressive writing should help students to learn that their primary purpose of writing is to explore and/or communicate their personal experience, their opinions about things, their response to the world, including the world of reading. We believe that this style of writing is focused on them as writers instead of an objective non-agentive force outside their being, or on an imaginary reader they might want to persuade.

Our experiential knowledge of students' writing has shown us that the act of composing can create problems for students, especially for those writing in a second language (L2) in academic contexts. Formulating new ideas can be difficult because it involves transforming or reworking information, which means that writing is more complex than telling (Myles, 2002). We believe that academic writing for L2 students requires conscious effort and practice in composing, developing, and analysing ideas. Students writing in their L2 have to acquire proficiency in the use of the language as well as in writing strategies, techniques and skills (Myles, 2002).We surmise that writing can contribute to every aspect of our lives. It can be an extension and reflection of all our efforts to develop and express ourselves in the world around us, to make sense of that world, and to impose order upon it. The philosophical and educational foundations of expressive writing presented themselves as a pedagogical tool we wanted to examine in this study.

\section{RESEARCH DESIGN}

Predicated on a qualitative methodology the study focused on how to support students to write more engaging, more expressive as well as more communicative texts (Colyar, 2008). In order to understand the dynamics and fall-outs of the issue at hand our study has adopted an interpretive approach involving analyses of students' written journal entries, document analysis and autobiographical writing.

The analyses enabled us to capture and describe the central themes that cut across the writing of all the participants. Gathering samples from their writings led us to see the development of variations in their writing patterns that would be of interest and value in capturing the central theme and shared aspects (Patton, 1990) for our research.

The fundamental aim of our research was therefore meant to improve the educational practice of expressive writing rather than to produce unbeneficial knowledge about what goes on in a language classroom. We used a constructivist approach in this study, in that we recognised that reality is a product of human intelligence interacting with experience in the real world. Andrew et al. (2011) argue that constructivism views reality as a construct of human mind, therefore reality is perceived to be subjective. Hence, we as researchers wanted the students to respond to the literature of daily living/an evolutionary nature through reading and writing. Literature of an evolutionary nature we defined as literature that affects emotions, motives, features of personality and forms of cognition. These were consistent with the need to examine the dynamics and outcomes of L2 writing influenced by the use of everyday literature.

Our decision to use a personal-response approach thus reinforced the primacy of writing as an educational practice. In light of this the research methodology which is proposed in this paper is primarily meant to point out the fluidity, provisionality and indeterminacy of the kind of meanings we expected to see in our students' writing (Bilton \& Sivasubramaniam, 2009). 


\section{RESEARCH INSTRUMENTS}

The programme based on the literature of daily living was implemented as an intervention at a university in the Western Cape. It spread over one semester of 12 weeks' duration and had fourteen participants. The intervention used authors' original narratives and expository works to support students' developing literacy. This approach was much more than giving students' quality literature; it was about doing authentic writing tasks with the literature providing support as they needed it.

We had two groups of students and classed them as noticeable and distinguished groups. We arranged the students in these groups to have a better control as to which students' writing had improved over the period in which the study was conducted. We never physically labelled the students and they had no idea that they had been categorised into groups. In keeping with the protocols of our ethical clearance we had mentioned to the students that we would not disclose their names. The students signed a consent form giving us permission to use their writings for our study.

Our research design allowed for triangulation through multiple sources of data collection: autobiographical writing, journals, and class assignments. The procedures we used in our study were deliberately kept open-ended as our intention was to create a free writing style, which is just writing forward, without judgement or concern for a polished product (Elbow, 1998) in an effort to develop students' expressive writing ability. The sheer variety of instruments indicates that there cannot be a single standard of evaluation of writing quality of the student-generated writing.

\section{DATA ANALYSIS AND DISCUSSION}

\section{The basis for data analysis}

We randomly placed the participants in two different groups, one being "the distinguished group", to whom we responded in general; that is to say we did not point out specific errors in the students' writing in this group and if an error interfered with understanding, we would just respond to the student that we did not understand what they meant and have them try again in their next entry. The "noticeable group" was responded to by using recasts, in which we highlighted the writing error and then responded with the acceptable form (hoping to encourage the noticing and realization of errors). We identified the two groups as one being noticeable, where we would be able to notice an improvement in the students' writing over a period of time and the other group was identified as distinguished because these students only wanted to participate in the study, but had no serious problems in their writing. At this juncture we hasten to state that for the purpose of this paper, we would only be able to present a select sampling of the data analysis collected with reference to three of the instruments used in the study: journal entries, class assignments and autobiographical writing and not the entire data set.

\section{Journal entries}

The students wrote in their journals for 12 weeks. Their journal entries helped us to determine what problems they might be experiencing in their writing. We have only included a few samples of their journal entries for want of more space in this paper. We believe that this type of more open writing also focuses on the process of writing while reflecting and exploring other ideas as observed by Auerbach (1999). All transcriptions have been provided verbatim. 
Noticeable 1: $\quad$ Examens are coming soon. I just realized that I am not yet ready. When I put it in my mind, I can feel the pressure on me. What shall I do to reduce that pressure? I do not know yet what to do. Applied Building Science and communication will be the more difficult exams, I think. One of my friend gave me a new name to our Communication subject. He now calls it A.C.S (Applied Communication Science).

Noticeable 2: $\quad$ After a long night, I wake up by 6:30 am, got ready for my tech, abide nervous because I was about to do my first power point presentation in communication subject on timetable. We had our first period on Construction Technology and finished earlier so that we can study to prepare our March Test.

Distinguished 1: Having to wake up at 07:00am after sleeping at 03:00am I felt like commit suicide. I might be exaggerating because I don't know how it feels to commit suicide but you can make the assumption that it was hard for me to wake up. Some people are just too damn lazy, especially in this class.

Distinguished 2: $\quad$ I feel like my life is in shambles! I can't begin to describe how things have taken a turn for the worst. I don't have a home, I hardly have clothes to wear cause all my things are at home and we can't go back without a protection order. I'm trying really hard to focus and get my head right but its difficult to do since I'm living out of a bag and in someone else's space.

If we look at what noticeable student 1 and 2 wrote we are able to get a sense of superficiality in their writing. Their sentence structures are problematic. For example, the sentence "Examens are coming soon." Which should be written "The exams is approaching." We notice that the incorrect tense was used. From the noticeable student 2 sentence, "After a long night, I wake up by 6:30 am, got ready for my tech,...". We notice a strong switch from past to present tense executed wrongly. If written correctly, it would read, "After a long night, I woke up at 6:30am, got ready for tech,...". In distinguished student 1 we notice words missing and the incorrect tense of the word. In the first sentence "... I felt like commit suicide." which should read "I felt like committing suicide." In distinguished student 2 we do not notice any serious grammatical mistakes. We do however sense a moment of freedom in their writing because especially with distinguished student 2 , providing us with very personal and emotional information which can be seen in the opening lines: "I feel like my life is in shambles!"

\section{Class assignments}

The following data were drawn from class assignments based on writing a paragraph. For the writing task done in this section, the students had to answer the following question, which was aimed at them writing freely and helping them to enhance their creative thinking. We wanted them to structure their writing by focusing on a particular topic. Although the writing is still personal, it is now supposed to be more focused. Our aim was for the student to give a personal-response to an event which they can relate to or be familiar with. Our intention was for the student to have less difficulty coming up with an answer, by awakening a memory they felt comfortable to write about. 


\section{1) Have you met anyone exceptionally interesting lately? Why was he or she so interesting?}

Noticeable 1: $\quad$ I once met a drug dealer and real criminal who did anything about crime, rape, house breaking, and high jecking cars all this kind of staff. He even tell us about how you feel after using drugs, like when you done to smoke you feel, like you alone in this world no body can tell you something. His storys were very interesting realy realy.

Noticeable 2: $\quad$ I once meet a manager of Russells in Elsies River. He is a funy man once you are around him you can not be quite. He will keep talking funy stuff jut to make you laugh. Russells manager is a good man whom a person can relay on. He is a good adviser, helper, and friendly. I was worried one day about my studies, I went to him then he gave me a good advise of how I can study, from that time I see him as an important person and interesting to be around.

Distinguished 1: $\quad$ I met Mrs Habane the Quantity Surveyor form Marry and Robberts. It was my wish to have an conversation with Qualified Quantity Surveyor. She was very kind and talkactive and I noticed that she is a good listener because of the way she looked at me while I was telling her how much I'm keen to be a Quantity Surveyor like her.

Distinguished 2: $\quad$ I once met a professional soccer player lately in Green Point Stadium. He was so amazing to see him playing with a ball. He was also able to relate the most and popular past events in soccer. He was able to speak four languages as the he travelled all over the world. He was able to speak French, English, Arabic and Afrikans. People around us were surprised to have a such well educated player who has good manners.

This was one of the first writing exercises the students undertook in class. These are real events which they wrote about. Noticeable student 1 had huge difficulties expressing himself. The first sentence was very problematic, but we were able to decipher what his intention was when he wrote: "I once met a drug dealer and real criminal who did anything about crime, rape, house breaking, and high jecking cars all this kind of staff." The beginning of the sentence is understandable, but the problems in the sentence structure may be viewed after "criminal". Here the student meant to say "...who knew everything about ..." Noticeable student 2 also made quite a few errors in his sentence structure. For example, "I once meet a manager of Russells in Elsies River. He is a funy man once you are around him you can not be quite." We see that the tense of "meet" is incorrect, which should be written "met" and maybe the student should have mentioned "Russells furniture store", which would have made it clear that he was referring to a furniture store. In the second sentence we notice the tense again being incorrect where the student should have written "He was a funny man. The distinguished student 1 and 2 made minor tense and spelling mistakes, but we understood what they were trying to say. We once again notice a very personal and focused response from the students to the question, so that they can be seen to develop confidence writing in a language that is not their mother-tongue. With the exception of Distinguished student 2, they 
all linked their writing to personal experiences and dreams. By drawing on personal memories, this exercise helped the students to come up with a suitable answer.

In the next task that they submitted, they had to supply an even more personal, but still focused response about themselves to the following question:

\section{2) When was the last time you accomplished something great? Explain.}

Noticeable 1: $\quad$ The last time I accomplished something great was when I received my matric. It was so hard in that year for me to make it because many things changed during the year. Trouble came in the family between my parents. That trouble supposed to bring a divorce between them. We overcame it with help of God. Reading with stress in mind is not easy at all. By getting my matric, I felt fulfilling something great I never had done before.

Noticeable 2: $\quad$ The last time I accomplished of something great was when our team won the Katongo Provincial cup in 2004. I was 15 at this period. The final game was played in a tour which was at $500 \mathrm{~km}$ from my hometown (Lubumbashi). It was my first time to be in a town that looks like a rural area. The final game was so hard because our opponents were very strong; and we had to bottle hard to win the final only after we reached the penalties. I was crying of joy when I received my medal and when I touched the Provial cup. How great it was!!

Distinguished 1: $\quad$ The last time I accomplished something great was when I received the Stalward award for the year 2012 at my high school. It felt amazing. It was an award I dreamed of getting ever since I was in grade 8 . I had never been nominated for nay of the categories at the Light House Awards event till I got to grade 11 when I was nominated for the second most prestigious award, after the Stalward award.

Distinguished 2: The last time I accomplished something great was when I was a soccer player. I scored 8 goal within 2 matches and I felt like a conqueror because that was not easy. Even a professional soccer player would never score 8 goals within 4 matches because it is not easy. That was my last great achievement in my life.

By the time the students completed this task, they had written in their journals for about one month and they were given quite a few grammar exercises to be completed at home on their own. These grammar worksheets were just guidance sheets for the students to work on in their own time and were not collected to be corrected. It seemed to us as if they had worked through the grammar worksheets, because their grammar improved and this influenced their writing skills. Let us look at the way noticeable student 1 begins his writing: "The last time I accomplished something great was when I received my matric." The sentence could be regarded as error-free. The only error which we picked up was in the last sentence, which should have read, "By getting my matric, I had fulfilled something great which I have never done before." We understood that achieving his matric was one of his greatest achievements. With noticeable student 2 we do not notice many mistakes in his sentence structure. For 
example, in the first sentence he should have written "The last time I accomplished something great..." With distinguished student 1 and 2 we notice a definite flow in the sentence structure as their ideas appear to be connected. We hardly see any sentence errors. We notice how the one thought fits in with the next thought in the sentence.

From these writing tasks that focused mainly on personal experiences we moved to a more abstract task where they had to make a formal argument - "The Most Important Word". In this case we required that the students first write a rough draft, then the final draft. Presented below is the final draft.

\section{3) Question read: What is the most important word in the English language?}

Below are students' responses to this question.

Noticeable 1: $\quad$ The most important word in the English Language is "Peace" peace is important because without it there will be wars around the world. When a country has a peace, The populal as well benefit from it by not fighting. Love and understanding each other by helping will bring peace within us and world will be in peace.

Noticeable 2: $\quad$ The most important word in the English Language is "respect". This word is important because it help considere other people despite our difference. When you respect someone, the more you are going to get something positive from that person. This word may push the world to have a new vision on how to treat people.

Distinguished 1: $\quad$ Love would be the most important word in the English Language. It is a word expressed amoung all human being, in so many different ways. The feeling of being loved is greater than any other feeling, as we all long to be loved. Even in the simplest way, in the form of a hug.

Distinguished 2: The most important word in the English Language is "Love". The word is important because it simbolises care, affection and respect among people. Care, affection and respect are fundamental factors or personalities that creates peace among people as well as the country as a whole. Leading to a crime free nation.

The data shown here came as a critical response to what the students understood in the question. We noticed that the students' responses affected the way they answered this question compared to the way they answered the questions in the previous writing tasks. We observed that they moved away from a personal-response to a more critical response in their writing. We were under the impression that this task was quite challenging because it is not that easy to identify the most subtle of the underlying qualities of expressive English. We noticed that both the noticeable and distinguished students had difficulty expressing themselves with this task. However, they took on the challenge and the point was for them to attempt this task and use critical thinking to come up with a suitable answer. Both the noticeable and distinguished students made mistakes. Noticeable student 1 meant to write "the population" and instead wrote "The populal" and noticeable student 2 wrote "... it helps consider..." Distinguished student 1 and 2 had few errors, like the spelling of the word 
"amoung" and "simbolises". As readers we understood what they were trying to say and we thought they justified their understanding of the most important English word sufficiently. In this exercise the students had moved away from a first person approach as seen in the previous two writing exercises to a more critical approach in this exercise.

We believe that the questions, "Have you met anyone interesting?" and "What was your greatest accomplishment?" allowed the students to give personal responses whereas, "What is the most important word in the English language?" encouraged the students to move to more critical responses in their writing.

\section{Autobiographical writing}

The following class assignment which was autobiographical writing, points to how expressive writing helped the students write better. At this stage we hasten to point out that the students had been writing in the journals for about three months as well as doing a huge amount of grammar exercises. Our data presented above indicate how autobiographical writing allows knowledge of ourselves and allows access to an organization of autobiographical memories which is shaped by the conventions of life stories and the way we are accustomed to interpreting those narratives (Harbus, 2009). What was the prompt?

\section{Noticeable 1: $\quad$ I wish I knew my father}

My life was not easy to be born without a father by myside. My mother was there for me yet I needed my father. Growing older without a male in our house becomes a big challenges to me. In 1999, on November at the age of 8 it was the first time I live in the house that rules by a man. I startet call any man I see around me a father to me. I never wanted to question my mother whose my father, because I thought she has the reasons why she never told me about him.

\section{Noticeable 2: $\quad$ My Uncle Christian}

My uncle Christian was ten years older than me. Despite, he was older than me we lived together as friend. I can even say that I was considered as his best friend at home. All informations concerning my uncle were collected from me. I was acting as his secretary. He used to encouraging me when I felt bad and shouted at me when I did wrong things.

In 2011, when I came in South Africa, my uncle gave me a gift and told me to be serious with my studies.

\section{Distinguished 1: $\quad$ My life, myself.}

Education is my legacy, that is what I say to myself everyday. However, getting myself educated without any parental guidance and support is an hectic challenge I face everyday of my life. I am one of the underprivileged kids born into a family where parents are divorced. Throwing me into the world of vending for myself. I hardly know my mum because I grow up with my grandma and my father is married to another another wife which keeps us apart.

\section{Distinguished 2: $\quad$ Grade eleven}

Life in grade eleven was becoming better and better, with the support of my mother and younger brother, Sisonke. The elections for the Excutive Committee members (prefects) was on the horizon. Having had a fair high school carreer thus far, I was confident that I could become a member. Academically I was not the best but I tried my best and having been a 
Student Representative Council for three consecutive years, showed I had leadership qualities.

By writing an autobiographical piece, which is very personal, we thought it would be integrating personally and emotionally meaningful writing instruction that would allow L2 writers to reflect on their personal experiences and to extend their self-understanding in relation to cultural, linguistic, and emotional factors (Chamcharatsri, 2013). This we see in their opening lines of this writing exercise/task: Noticeable 1: "My life was not easy to be born without a father by myside. My mother was there for me yet I needed my father. Growing older without a male in our house becomes a big challenges to me." And noticeable 2: "My uncle Christian was ten years older than me. Despite, he was older than me we lived together as friend. I can even say that I was considered as his best friend at home." In this exercise we notice a better flow in their sentence structures as the one idea connects with the next. Students are using conjunctions like "despite", "however".

At this stage it seemed to us that students had grasped what expressive writing entailed by them writing very personal things about themselves and entering into a sensitive part of their lives which they were sharing with the reader. We thought that by allowing our students to write about personal history, we would be encouraging them to embrace L2 writing as a platform to negotiate their identities, finding power and legitimacy in the second language (Park, 2013b). It should be noted here that their writing should be viewed as a continuum of engagement and participation in the educational and social practices of writing.

\section{DISCUSSION OF FINDINGS}

The epistemological stance of our study was meant to challenge the assumption that individuals and their behaviour in tasks can be controlled and objectivized, for example by limiting the academic literacy programmes to academic tasks and strict rules about how you should write. As evidenced by our data, using the power of our students' consciousness showed their ability to construct an environment that they felt comfortable in and the classroom became a real-world location which they explored through the use of expressive writing.

Our journal entry data support the observation of our L2 students' sense of growing confidence and identity as writers which directed their personalized writing to reinforce our belief that writing can be meaningful to the students only when they are allowed to express emotional and seemingly irrational aspects in their thinking and acting (Kohonen et al., 2001). An example of this is seen when noticeable student 1 writes: "Examens are coming soon. I just realized that I am not yet ready. When I put it in my mind, I can feel the pressure on me. What shall I do to reduce that pressure?" The use of the first person and the emotion expressed in the word 'pressure', as well as the self-doubting question at the end show the personal engagement with the writing task.

We believe that one of the greatest benefits of writing in a journal is that it can/will help students get over the fear that they may have of writing in a non-native language and that it may lead to more self-confidence and a willingness to write (Jones, 1991a \& Voit, 2009: 18). It seems that students may feel threatened to write at first, but after some encouragement and experience writing in a non-threatening context about a subject matter they enjoy, will help develop confidence and a more open attitude toward writing (Jones, 1991a \& Voit, 2009: 18). 
The students used their class assignments to practise expressive writing. In doing so, they appeared to have learned to write better by moving along the continuum of increasing responsiveness. Such responsiveness is clear from the nature of their responses in that the students trusted the process by being at ease about sharing their personal experiences in life in their autobiographical writing. Their sentences show a fluency, in that their ideas were linked from one sentence to the next. As a result, they were able to develop their analytical ability and relate it to the experiential aspects of their reading and writing 'response'. The Noticeable group were able to address the topic but they had some difficulty developing their ideas. Their use of language revealed some let-downs and a weak focus on detail. The Distinguished group was able to address the topic using sufficient detail and showed some sentence variety and vocabulary. We noticed that in the first two assignments the students wrote in first person, making their response come across as personal and then moving on to a more critical approach in the third assignment.

Our aim with these writing tasks given to the students was to move them away from a personal approach to a more critical approach. This is seen when they responded to particular questions and to the assignment on what they thought the most important English word is. We believe with this task the students had to execute some critical thought to the answer which they supplied.

Our data from the autobiographical writing suggest that the most prominent features of those stories - event causality and sequence - can shape both written and oral narratives. It appears that standing foremost in an autobiographer's strategy is the element of character: his sense of self, of place, of history, of his motives for writing (Howarth, 1974: 365). In addition, there is the element of technique, where these components (autobiographer's strategy) have not received the attention they deserve, with the exception of some promising work on style (Howarth, 1974). An example of this is seen with noticeable student 1: "My life was not easy to be born without a father by myside. My mother was there for me yet I needed my father. Growing older without a male in our house becomes a big challenges to me." This example shows that style, then, is not subservient to content, but is a formal device significant in its own right. As viewed in Howarth's (1974: 366) study even the simplest stylistic choices, of tense or person, referring to first person "I or me", are directly meaningful, since they lead to larger effects, like those of metaphor and tone. By analyzing these elements in sequence we were able to trace an outline of our students' strategy, distinguishing their achievement from other works while affirming their place in the literary tradition.

In sum the data analyzed in this paper can reinforce our conceptualization of learning to write, in which our students attempted to learn to write as a lived-through experience. Our strategy shows how our students' writing moved from an unstructured to a structured domain, in that the formal writing still remained personal. Our intended teaching plan was to get the students to move from personal response writing tasks to a more critical writing response task. In this respect their writing has not only become 'their own' or 'authentic' but has also become a valuable creation in the context of study as it is 'eminently aesthetic' by virtue of it being plausible in that the student was to express their personal experiences in writing and permeable by exposing their selves in writing (Kramsch in Lantolf, 2000: 152). Most importantly, we believe that the students' helped themselves to appreciate and believe the immediacy and primacy of the meanings and the knowledge that they created through the use of expressive writing. 


\section{CONCLUSION}

Our investigation was mainly intended to observe and describe the dynamics and ramifications of an L2 phenomenon set off by the deployment of literature of an evolutionary nature. Our intention in this study was to explore a possible escape route from the formal structured manner of teaching academic literacy to engagement of our students through expressive writing, and reported and experimented writing samples that lead to introduce one kind of expressive writing responding to personal writing in the journal or autobiography. Having realized that voicing their emotions will not in any way result in negative assessment the students expressed themselves in different ways unique to their sociocultural backgrounds. There is some sense of tolerance of ambiguity that began to develop in the students as seen in these entries. These entries appear to suggest that the perceived problems of the students did not in any way cause them to 'freeze up' or be swayed by their inhibition completely (Arnold, 1999: 63).

There is not one single right form of writing which promotes expressive writing, but rather that an informed way of writing by getting the students to use personal response writing tasks help promote fluency in writing. We found that there was a kind of emotional release that came as a result of students expressing themselves in their writing. Our study aimed at encouraging our students to view their writing as personal constructions of meanings and that they should try and use their journal entries and class assignments to operationalize their effective and emotive use of language. We observed the motivating force of fluency that came about as a natural outcome through their attempts to write and this helped them to overcome the barriers that accuracy imposes on writers.

With the use of literature of an evolutionary nature we viewed its presence in our study as a promotion of continuous 'response' by the students. By sustaining the students' motivation to write, literature of this nature appeared to have promoted the students' proficiency and fluency in our investigation. The writing fluency that was seen particularly in their autobiographical writing where the students wrote about themselves and dealt with text of an evolutionary nature, encouraged the students to learn through a response of dealing with topics which dealt with daily living, like fears, joy, hopes, doubts, initiations, intuitions which constitute the route of expressive writing. Viewed in light of the aim, rationale, scope and contextual setting of our study, our close-knit explanations can serve as our warrant (Edge \& Richards, 1998) to justify the outcomes of our investigation.

Instead of imposing some predetermined order, teachers in South Africa should start asking students about their intentions and focus on the discrepancies that exist between what the writer wanted to communicate and what is in fact communicated. The educational rationale of this study was to discuss what is on the paper which can maximise the emotional drive of the students and this we believe will assist them to become better thinkers through expressive writing. By the same token, we believe that the evolution and existence of democratic citizenry cannot accrue in the absence of good thinkers and writers. Given this we reasonably assume that all those students who are initiated into expressive writing can eventually have a role to play in the functioning of democracy especially in South Africa which has gone through the ravages of apartheid and which is desperately in need of social as well as human capital (Rosenblatt, 1995). 


\section{REFERENCES}

ABBOTT, R, VW BERNINGER, \& M FAYOL. 2010. Longitudinal relationships of levels of language in writing and between writing and reading in grades 1 to 7 . Journal of Educational Psychology 102: 281-298.

ANDREW, PS, PM PEDERSON \& CD MCEVOY. 2011. "Research Methods and Designs in Sport Management" Human Kinetics.

ARNOLD, J. (ed.).1999. Affect in Language Learning. Cambridge: Cambridge University Press.

AUERBACH, E. 1999. The power of writing, the writing of power: Approaches to adult ESOL writing instruction. "Focus on Basics, 3"(D) 1: 3-6.

BERNINGER, V. D MIZOKAWA \& R BRAGG.1991. Theory-based diagnosis and remediation of writing disabilities. Journal of School Psychology 29: 57-79.

BERNINGER, V, A CARTWRIGHT, C YATES, L SWANSON \& R ABBOTT. 1994. Developmental skills related to writing and reading acquisition in the Intermediate grades. Reading and Writing: An Interdisciplinary Journal 6: 161-196.

BILTON, L \& S SIVASUBRAMANIAM. 2009. An inquiry into expressive writing: a classroom-based study. Language Teaching Research 13(3): 301-320.

CHAMCHARATSRI, P. B. 2013. Emotionality and second language writers: Expressing fear through narrative in Thai and English. L2 Journal 5(1): 59-75.

COLYAR, J. 2008. Becoming Writing, Becoming Writers. Qualitative Inquiry 15(2): 421436.

CROSSLEY, SA, JL WESTON, ST SULLIVAN \& DS MCNAMARA. 2011. The Development of Writing Proficiency as a function of Grade Level: A Linguistic Analysis. Written Communication 28 (3): 282-311.

EDGE, J \& K RICHARDS. 1998. May I See Your Warrant, Please?: Justifying Outcomes in Qualitative Research. Applied Linguistics 19(3): 334-356.

ELBOW, P. 1998. Writing Without Teachers. 25 ${ }^{\text {th }}$ Anniversary Ed. New York: Oxford University Press.

FOULK, D. \& HOOVER, E. 1996. Incorporating Expressive Writing into the Classroom. Technical Report Series.16. Minnesota: University of Minnesota.

GRAHAM, S \& KR HARRIS. 1989. Improving learning disabled students' skills at composing essays: Self-instructional strategy training. Exceptional Children. National Institutes of Health 59: 201-214.

HARBUS, A. 2009. Written Autobiography as a Source of Influence on Autobiographical Memory. ASCS09: Proceedings of the $9^{\text {th }}$ Conference of the Australasian Society for Cognitive Science. 126-130.

HASWELL, R. H. 2000. Documenting improvement in college writing: A longitudinal approach. Written Communication 17: 307-352.

HAYES, J \& L FLOWER. 1980. Identifying the organization of the writing process. In LW Gregg, L.W. \& Steinberg, E.R. (eds.), Cognitive processes in writing. Hillsdale, NJ: Erlbaum. 3-30.

HOWARTH, W.L. 1974. New Literary History. Changing Views of Character. The Johns Hopkins University Press. 363-381.

HUNT, KW. 1965. Grammatical structures written at three grade levels (NCTE Research Report Number 3). Urbana, IL: National Council of Teachers of English.

JONES, P. 1991a. The Various Beneits of Dialogue Journals. In J.K. Peyton \& J. Staton (eds.), Writing Our Lives: Reflections on Dialogue Journal Writing with Adults Learning English. Englewood Cliffs, NJ: Prentice Hall Regents. 102-126.

KERN, R. 2000. Literacy and Language Teaching. Oxford: Oxford University Press.

Per Linguam 2016 32(2):95-108

http://dx.doi.org/10.5785/32-2-654 
KOHONEN, V, R JAATINEN, P KAIKKONEN \& J LEHTOVAARA. 2001. Experiential Learning in Foreign Language Education. Harlow: Longman.

LANTOLF, J.P. (ed.). 2000. Sociocultural Theory and Second Language Learning.Oxford: Oxford University Press.

MCCUTCHEN, D. 1986. Domain knowledge and linguistic knowledge in the development of writing ability. Journal of Memory and Language 25: 431-444.

MCCUTCEN, D \& C PERFETTI. 1982. Coherence and connectedness in the development of discourse production. Text 2: 113-139.

MYLES, J. 2002. Second Language Writing and Research: The Writing Process and Error Analysis in Student Texts. TESOL Quarterly 6(2).

NUNN, R \& S SIVASUBRAMANIAM. 2011. From defining EIL competence to developing EIL learning. Pusan: Asian EFL press/ A Division of Time Taylor International.

PARK, G. 2013b. 'Writing is a way of knowing': Writing and identity. ELT Journal 67: 336345.

PATTON, M. 1990. Qualitative Evaluation and Research. Beverley Hills, CA: Sage.

PAVLENKO, A.1998. Second language learning by adults: Testimonies of Bilingual writers. Issues in Applied Linguistics 9(1): 3-19.

PERFETTI, C \& D MCCUTCHEN. 1987. Schooled language competence: Linguistic abilities in reading and writing. In S. Rosenberg (Ed.), Advances in Applied Psycholinguistics. Cambridge, UK: Cambridge University Press. 105-141.

ROSENBLATT, L. 1995. Literature as Exploration, New York: The Modern Language Association of America.

RUSSELL, G, S BAKER \& L EDWARDS. 1999. Teaching Expressive Writing to Students with Learning Disabilities. ERIC/OSEP Digest E590: 1-7.

SIVASUBRAMANIAM, S. 2004. An investigation of L2 students' reading and writing in a literature-based language programme: Growing through responding. Unpublished $\mathrm{PhD}$ Thesis, University of Nottingham, UK.

VOIT, M. 2009. Do dialogue journals with recasts improve the writing skills for adult learners with limited literacy skills? Master of Arts in ESL. Hamline University. Saint Paul. Minnesota.

WITTE, SP \& L FAIGLEY. 1981. Coherence, cohesion, and writing quality. College Composition and Communication 32: 189-204.

\section{BIOGRAPHICAL NOTES}

Verbra Pfeiffer is a post doctorate researcher in the Curriculum Studies Department of the Education Faculty at the University of Stellenbosch. She has been a second and foreign language educator for fifteen years and taught English at every grade level ranging from preschool to university including language centres. She has taught in Switzerland, Germany and South Africa. Her research interests include academic literacy pedagogy, second language advocacy and literature-based language pedagogy. Email: vfpfeiffer@sun.ac.za

Dr. Sivakumar Sivasubramaniam is Professor and Head of Language Education in the Faculty of Education at the University of the Western Cape and a NRF researcher. He has taught English in India, Ethiopia, Thailand, Bahrain, Armenia, and the U.A.E. His research interests include response-centred reading/ writing pedagogies, literature-based language pedagogies, constructivism in EIL, second language advocacy, narratives in language education and text-based approaches to academic and social literacy practices.

Email: ssivasubramaniam@uwc.ac.za and sivakumar49@yahoo.com 